\title{
ESTUDO E AVALIAÇÃO DE UM SISTEMA HÍBRIDO MEMBANA-RESINA TROCADORA DE ÍONS PARA OBTENÇÃO DE ÁGUA COM BAIXA CONDUTIVIDADE ELÉTRICA
}

\author{
F. J. QUEIROZ ${ }^{1}$, F. A. R. MARQUES ${ }^{1}$, J. U. L. BEZERRA ${ }^{2}$, \\ R. V. ALVES ${ }^{1}$ e K. B. FRANÇA ${ }^{1}$ \\ ${ }^{1}$ Universidade Federal de Campina Grande, Unidade Acadêmica de Engenharia Química \\ ${ }^{2}$ Universidade Estadual da Paraíba, Departamento de Química \\ E-mail para contato: josimar.queiroz@eq.ufcg.edu.br
}

\begin{abstract}
RESUMO - Para atender tanto a demanda para consumo humano como industrial, o processo de osmose inversa vem sendo bastante utilizado ao longo das últimas décadas. A utilização de resinas de troca iônica, aniônica e catiônica, é empregada visando obtenção de água com baixa condutividade elétrica. Com isso, o objetivo deste trabalho é avaliar o desempenho de um protótipo de laboratório constituído por seis elementos de membrana de osmose inversa e dois leitos mistos de resina trocadora de íons, para produção de água com baixa condutividade elétrica. A avaliação foi realizada em termos de parâmetros físico-químicos da água de alimentação, assim como após passagem pelo sistema de membranas, e por cada uma das colunas de resina de troca iônica utilizadas. Foi possível obter água com baixa condutividade elétrica, o que confirma o potencial do sistema para aplicação em processos que requerem água ultrapura.
\end{abstract}

\section{INTRODUÇÃO}

Com a crescente demanda por água de boa qualidade, não apenas para o consumo humano, mas também para as mais variadas aplicações, algumas tecnologias de purificação de águas vêm sendo aplicadas como alternativa para o problema, o processo de separação por membranas de osmose inversa assim como as resinas trocadoras de íons são processos eficientes.

\subsection{MEMBRANAS DE OSMOSE INVERSA}

Os processos que utilizam membranas como barreira seletiva começaram a surgir a partir do início da década de 70, em adição a processos clássicos como: destilação, filtração, absorção, troca iônica, centrifugação, extração por solvente, cristalização (Habert et al., 2006). Uma membrana é uma barreira que separa a solução de alimentação em duas fases (permeado e concentrado), restringindo, total ou parcialmente, o transporte de uma ou várias espécies químicas presentes nas fases (Habert et al., 2006), conforme a Figura 1. 
Figura 1 - Membrana em módulo espiral e os componentes

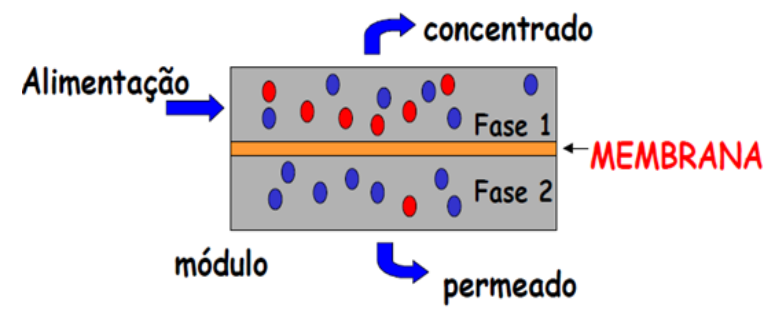

A osmose inversa, ou hiperfiltração, acontece quando uma pressão mecânica superior à pressão osmótica é aplicada no lado da solução mais concentrada, dessa forma o sentido do fluxo de solvente que atravessa a membrana é invertido, possibilitando a obtenção de uma corrente de água purificada isenta de sais, vírus, bactérias e fungos (FERREIRA et al., 2007). O processo é representado na Figura 2 (Silva et al., 2008).

Figura 2 - Representação do processo de osmose inversa

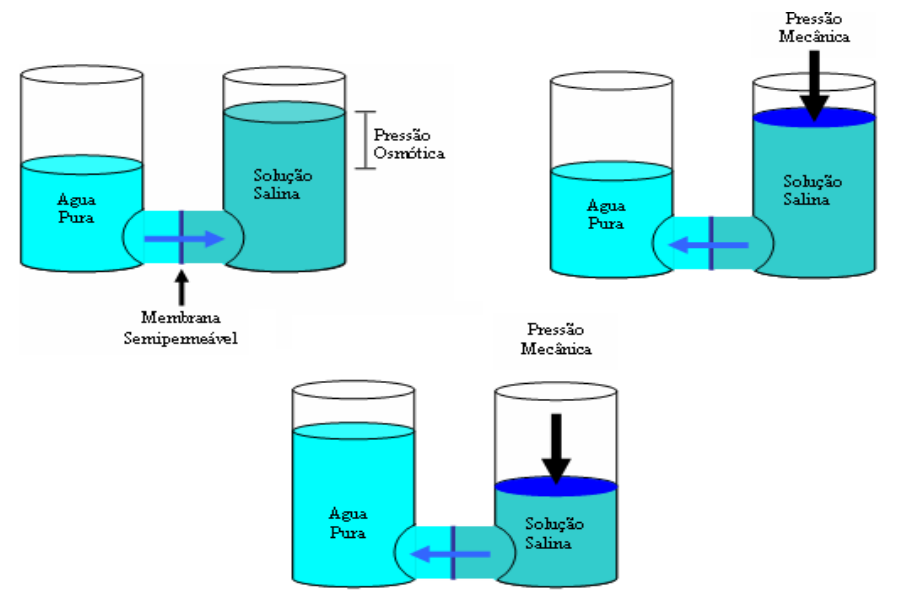

Segundo Amjad (1993), a taxa de transporte de água através da membrana depende de algumas propriedades desta: temperatura, diferença de pressão aplicada, diferença da pressão osmótica entre a solução mais concentrada e a de menor concentração. As membranas mais utilizadas são feitas de poliamida aromática; elevadas taxas de rejeição de sais e de moléculas orgânicas superiores são observadas, e apresentam uma ampla faixa de temperatura de operação, variando de 0 a $45^{\circ} \mathrm{C}$ (Silva, 2008).

\subsection{RESINAS DE TROCA IÔNICA}

As resinas são bastante utilizadas em indústrias, visando à purificação de águas para a alimentação de caldeiras, obtenção de água pura para química fina, extração de materiais orgânicos e coloides, bem como a extração de metais pesados (Pohl, 2006). Segundo Silva et al. (2007) quando a troca iônica ocorre, os íons H+ e OH- são liberados na água que se encontra em contato com a resina, reagindo entre si como forma de neutralizar a água purificada formando uma nova molécula de água a cada instante, conforme a Figura 3 (Silva et al., 2007). 
Figura 3. Processo de troca iônica em resinas aniônica e catiônica

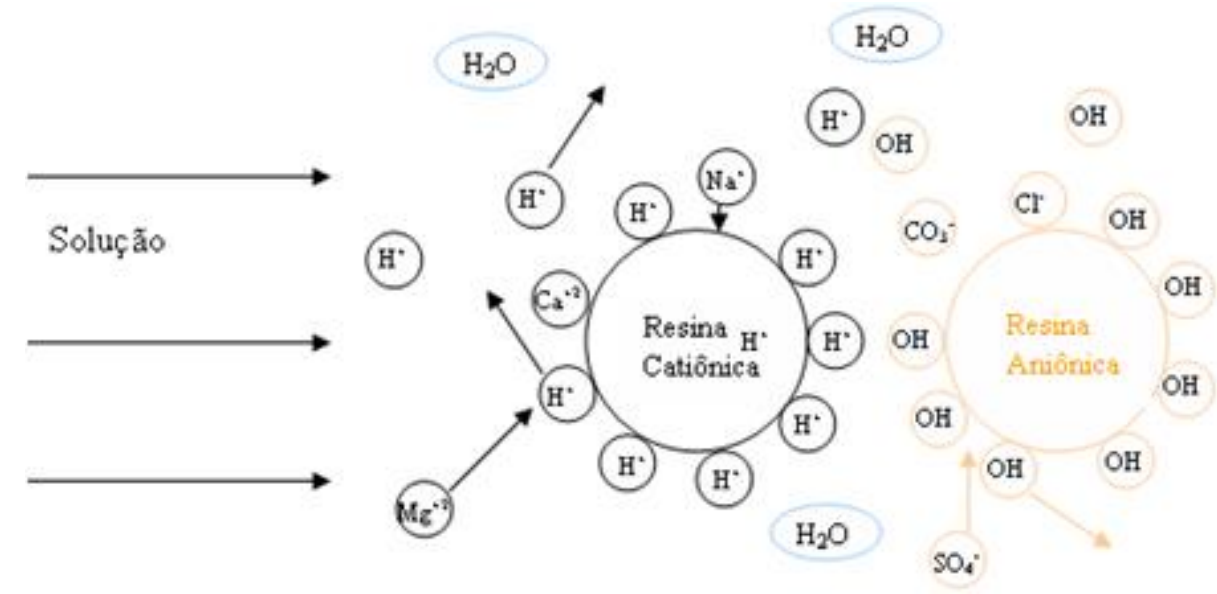

\section{MATERIAIS E MÉTODOS}

O presente trabalho de pesquisa foi desenvolvido no Laboratório de Referência em Dessalinização (LABDES), da Unidade Acadêmica de Engenharia Química, na Universidade Federal de Campina Grande (UFCG).

O sistema de dessalinização via osmose inversa é constituído por seis elementos de membranas de poliamida aromática com 2,5" de diâmetro e 14" de comprimento com pressão de operação igual a de $4,0 \mathrm{kgf} / \mathrm{cm}^{2}$ na entrada das membranas, uma bomba de alta pressão de aço inox, conectada a um tanque de alimentação de capacidade volumétrica de 200 litros. A desmineralização por troca iônica foi realizada por duas colunas que utilizam resinas catiônica e aniônica. A Figura 5 mostra o sistema híbrido de membrana-resina utilizado.

Figura 4 - Sistema híbrido membrana-resina

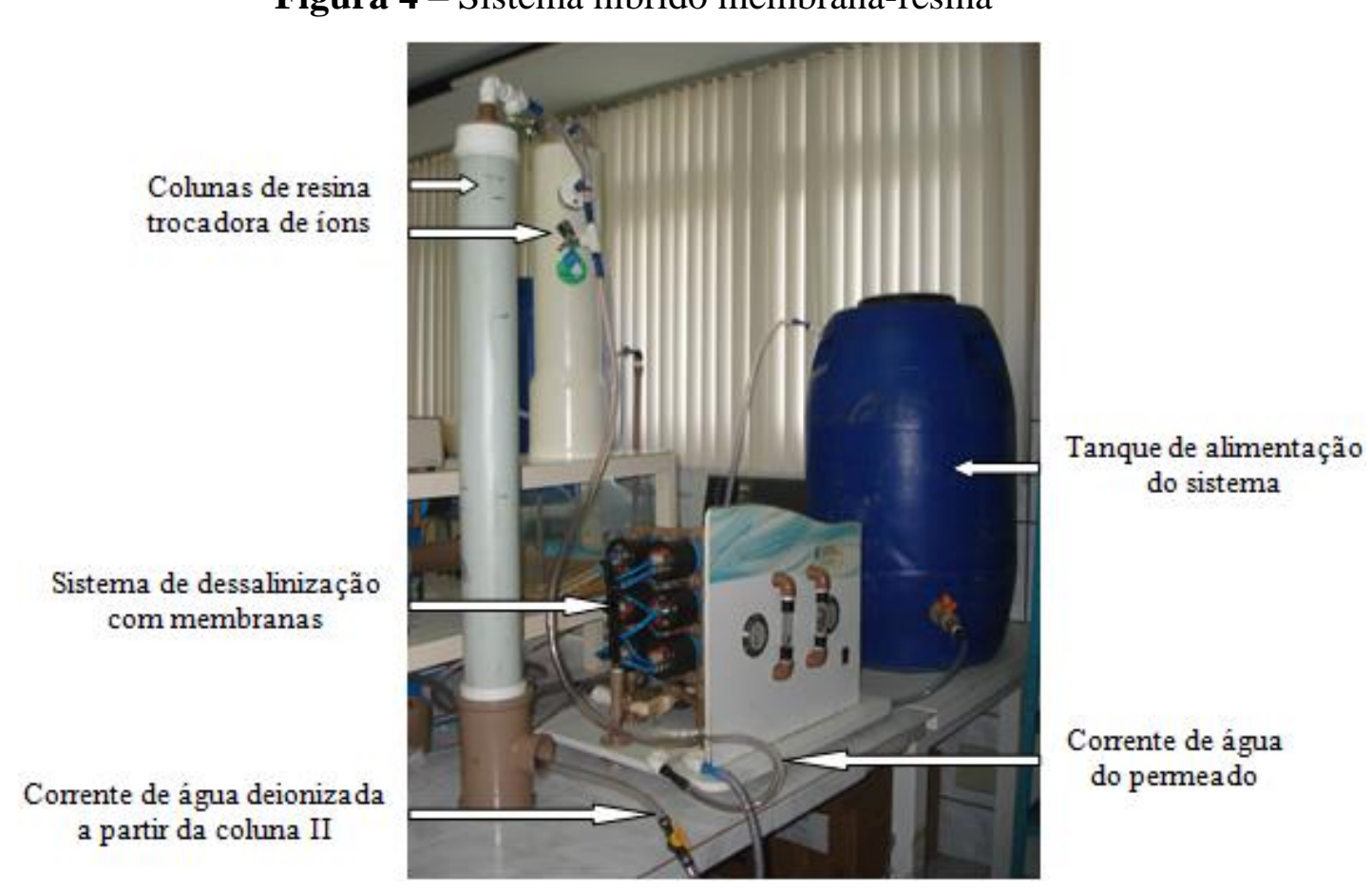


A água de alimentação do sistema foi proveniente do abastecimento local da cidade de Campina Grande, Paraíba, juntamente com água coletada da chuva. Realizou-se análise físico-química desta, bem como após passagem pelo sistema de membranas, e coluna de resina de troca iônica 1 e 2. Os métodos utilizados para realização das análises físico-químicas das amostras de água seguem o Standard Methods For Examination Of Water And Wastewater 2012.

\section{RESULTADOS E DISCUSSÕES}

O Quadro 1 mostra os boletins técnicos físico-químicos referentes a amostra de água da alimentação, após passagem pelo sistema de membranas, e após passagem nas colunas de resina de troca iônica 1 e 2 .

Quadro 1 - Boletins físico-químicos referentes as amostras de água coletadas.

\begin{tabular}{|c|c|c|c|c|}
\hline Parâmetro & Alimentação & $\begin{array}{c}\text { Após passagem } \\
\text { no sistema } \\
\text { de membranas }\end{array}$ & $\begin{array}{l}\text { Após passagem } \\
\text { na coluna } 1\end{array}$ & $\begin{array}{l}\text { Após passagem } \\
\text { na coluna } 2\end{array}$ \\
\hline $\begin{array}{c}\text { Condutividade Elétrica, } \\
\mu \mathrm{mho} / \mathrm{cm} \text { a } 25{ }^{\circ} \mathrm{C}\end{array}$ & 839,7 & 57,6 & 1,8 & 1,6 \\
\hline Potencial Hidrogeniônico, $\mathrm{pH}$ & 8,2 & 7,4 & 6,5 & 6,3 \\
\hline Turbidez, (uT) & 1,3 & 0,4 & 0,5 & 0,4 \\
\hline $\begin{array}{l}\text { Cor, Unidade Hazen } \\
\text { (mg Pt-Co/L). }\end{array}$ & 10,0 & 0,0 & 0,0 & 0,0 \\
\hline $\begin{array}{c}\text { Dureza em Cálcio }\left(\mathrm{Ca}^{++}\right), \\
\mathrm{mg} / \mathrm{L}\end{array}$ & 26,4 & 0,8 & 0,1 & 0,1 \\
\hline $\begin{array}{l}\text { Dureza em Magnésio } \\
\left(\mathrm{Mg}^{++}\right), \mathrm{mg} / \mathrm{L}\end{array}$ & 29,4 & 1,1 & 0,0 & 0,0 \\
\hline $\begin{array}{c}\text { Dureza Total }\left(\mathrm{CaCO}_{3}\right), \\
\mathrm{mg} / \mathrm{L}\end{array}$ & 188,5 & 6,8 & 0,3 & 0,3 \\
\hline Sódio $\left(\mathrm{Na}^{+}\right), \mathrm{mg} / \mathrm{L}$ & 101,2 & 8,9 & 0,0 & 0,0 \\
\hline Potássio $\left(\mathrm{K}^{+}\right), \mathrm{mg} / \mathrm{L}$ & 4,1 & 0,3 & 0,0 & 0,0 \\
\hline Alumínio $\left(\mathrm{Al}^{3+}\right), \mathrm{mg} / \mathrm{L}$ & 0,00 & 0,00 & 0,00 & 0,00 \\
\hline Ferro Total, mg/L & 0,03 & 0,01 & 0,01 & 0,00 \\
\hline $\begin{array}{c}\text { Alcalinidade em Hidróxidos, } \\
\mathrm{mg} / \mathrm{L}\left(\mathrm{CaCO}_{3}\right)\end{array}$ & 0,0 & 0,0 & 0,0 & 0,0 \\
\hline $\begin{array}{c}\text { Alcalinidade em Carbonatos, } \\
\mathrm{mg} / \mathrm{L}\left(\mathrm{CaCO}_{3}\right)\end{array}$ & 0,0 & 0,0 & 0,0 & 0,0 \\
\hline $\begin{array}{c}\text { Alcalinidade em Bicarbonatos, } \\
\mathrm{mg} / \mathrm{L}\left(\mathrm{CaCO}_{3}\right)\end{array}$ & 75,6 & 4,0 & 1,4 & 0,6 \\
\hline $\begin{array}{l}\text { Alcalinidade Total, } \\
\mathrm{mg} / \mathrm{L}\left(\mathrm{CaCO}_{3}\right)\end{array}$ & 75,6 & 4,0 & 1,4 & 0,6 \\
\hline Sulfato $\left(\mathrm{SO}_{4}^{--}\right), \mathrm{mg} / \mathrm{L}$ & 17,2 & 4,3 & 4,1 & 3,8 \\
\hline Fósforo Total, mg/L & 0,0 & 0,0 & 0,0 & 0,0 \\
\hline Cloreto $\left(\mathrm{Cl}^{-}\right), \mathrm{mg} / \mathrm{L}$ & 243,5 & 20,9 & 3,6 & 2,1 \\
\hline Nitrato $\left(\mathrm{NO}_{3}{ }^{-}\right), \mathrm{mg} / \mathrm{L}$ & 0,13 & 0,04 & 0,04 & 0,00 \\
\hline Nitrito $\left(\mathrm{NO}_{2}^{-}\right), \mathrm{mg} / \mathrm{L}$ & 0,02 & 0,00 & 0,00 & 0,00 \\
\hline Amônia $\left(\mathrm{NH}_{3}\right), \mathrm{mg} / \mathrm{L}$ & 0,07 & 0,00 & 0,00 & 0,00 \\
\hline Sílica, mg/L $\left(\mathrm{SiO}_{2}\right)$ & 3,7 & 0,0 & 0,0 & 0,0 \\
\hline $\begin{array}{c}\text { STD (Sólidos Totais } \\
\text { Dissolvidos a } 180^{\circ} \mathrm{C} \text { ), } \mathrm{mg} / \mathrm{L}\end{array}$ & 518,0 & 41,4 & 9,6 & 6,8 \\
\hline
\end{tabular}


Após passagem pela coluna de troca iônica I, obteve-se reduções em todos os parâmetros avaliados e após a passagem pela coluna II os íons diminuíram a valores próximos a zero. Assim, houve eliminação quase total de todos os íons, com exceção do sulfato. $\mathrm{O}$ grupo funcional trimetilamonio da resina, que tem seletividade para o sulfato, possivelmente não está realizando de maneira adequada sua função. A alternativa utilizada para resolver esse problema será realizar o processo de regeneração das resinas, para que estas possam ter sua eficiência máxima. As análises físico-químicas se mostram indispensáveis, pois só assim se pode saber a qualidade da água que está sendo utilizada com determinada finalidade. E a partir disso, dependendo dos resultados e do que se objetiva, estudar alternativas para resolver eventuais problemas encontrados ou melhorar o processo.

\section{CONCLUSÕES}

As membranas de osmose inversa bem como as resinas de troca iônica mostraram grande poder de redução de íons, fornecendo água de qualidade em termos de baixa condutividade elétrica. Os resultados obtidos mostram que estes processos associados podem fornecer água de excelente qualidade, suprindo variadas necessidades.

A água proveniente das resinas é utilizada em laboratório para preparação de soluções e lavagem de vidrarias, e certamente é uma alternativa para fins industriais que exigem elevada pureza, como na indústria de microchips, biotecnologia, na área de saúde (para aplicação no processo de hemodiálise, por exemplo).

\section{REFERÊNCIAS}

AMJAD, Z. Reverse Osmosis: Membrane Technology. Water Chemistry \& Industrial Aplications. Van Nostrand Reinhold: New York. 1993.

FERREIRA, W. B.; GURJÃO, K. O.; MONTEIRO, G. S.; SILVA, J. N.; FRANÇA, K. B. Estudo da alcalinidade em carbonato e bicarbonato de cálcio na água de alimentação de um sistema de dessalinização de osmose inversa (OI) submetido à pré-tratamento físicoquímicos. XLVII Congresso Brasileiro de Química. Natal. 2010.

SILVA, J. I. S.; SILVA, S. K.; FRANÇA, K. B. Análise da regeneração de resinas Trocadoras de íons para fins de desmineralização de águas. VII Congresso Brasileiro de Engenharia Química em Iniciação Científica. São Carlos. 2007.

SILVA, S. K. Sistema de dessalinização da comunidade de Uruçu - São João do Cariri - PB: Análises, monitoramento e avaliação de um misturador para o uso do concentrado. 122p. Dissertação de mestrado em Engenharia Química. Universidade Federal de Campina Grande. Campina Grande. 2012.

EATON, A. D.; RICE, E. W.; BIRD, BAIRD, R.B.; CLESCERI, L.S. (editors). Standard Methods for the Examination of Water and Wastewater: Centennial Edition. 22nd Edition. American Public Health Association: Washington, D.C. 2012.

POHL, P. Application of ion-exchange resins to the fractionation of metals in water, v. 25, p. 31-43, 2006. 